\title{
PENGARUH PEKERJAAN ORANG TUA TERHADAP CITA-CITA ANAK
}

\author{
Nadia Try Agustyani ${ }^{1}$, Tin Rustini², Yona Wahyuningsih ${ }^{3}$ \\ Univesitas Pendidikan Indonesia Kampus Cibiru ${ }^{1,2,3}$ \\ 1Nadiatrya15@upi.edu \\ 2Tinrustini@upi.edu \\ 3yonawahyuningsih@upi.edu
}

\begin{abstract}
This study aims to find out the influence of parental work on children's ideals. This type of research uses correlational descriptive research. With the research subject is a student of grade IV B SDN Sukalarang Kab Sukabumi which amounted to 48 students with respondents taken, namely as many as 18 respondents. Data collection technique is by using questionnaires that are shared directly with students. The data analysis technique used in this study used a Chi-square nonparamatric statistical test with a significance level of 0.05 . Based on the research conducted the results showed that the work of parents had absolutely no effect on the ideals of the child. Children have their own desires and decisions about their goals.
\end{abstract}

Keywords: mind, parens, education

\begin{abstract}
ABSTRAK
Penelitian ini bertujuan untuk mengetahui pengaruh pekerjaan orang tua terhadap cita-cita anak. jenis penelitian ini menggunakan penelitian deskriptif korelasional. Dengan subjek penelitian adalah siswa kelas IV B SDN Sukalarang Kab Sukabumi yang berjumlah 48 siswa dengan responden yang diambil yaitu sebanyak 18 responden. Teknik pengumpulan data yaitu dengan menggunakan kuesioner yang dibagikan langsung kepada siswa. Teknik analisis data yang digunakan dalam penelitian ini menggunakan uji statistik non parametrik Chi-square dengan taraf signifikasi 0,05 . Berdasarkan penelitian yang dilakukan hasil menunjukkan bahwa pekerjaan orang tua sama sekali tidak berpengaruh terhadap cita-cita anak. Anakanak memiliki keinginan dan juga keputusannya sendiri terhadap cita-citanya.
\end{abstract}

Kata Kunci: cita-cita, pekerjaan orang tua, pendidikan

\section{A. Pendahuluan}

Pendidikan pada saat ini merupakan sebuah kebutuhan yang primer. Pendidikan sangat memegang peranan yang sangat penting dikehidupan kita. Ini artinya bahwa setiap manusia berhak untuk mendapatkan Pendidikan. Dalam 
pembukaan Undang-Undang Dasar 1945 juga dicantumkan tentang harapan Pendidikan "Mencerdaskan kehidupan bangsa" merupakan salah satu cita-cita bangsa Indonesia. Dari sini diharapkan bahwa Pendidikan nasional yang mengglobal rakyat Indonesia dapat, mencerdaskan sehingga memiliki kecerdasan pengetahuan keterampilan dan psikomotorik.

Pada saat kita terlahir kedunia kita sudah mulai mengenal Pendidikan. Pendidikan yang pertama kali didapat yaitu Pendidikan dilingkungan keluarga atau Pendidikan informal. Pendidikan informal merupakan Pendidikan yang diperoleh oleh sesorang dari kehidupan sehari-hari yang tanpa disadari atai tidak sadar. Pendidikan informal ini berlangsung seumur hidup dari mulai lahir sampai mati (Sidik et al., 2013).

Pendidikan terbagi menjadi ke dalam dua kelompok yaitu Pendidikan secara formal dan Pendidikan non formal (Fansen, 2020). Berdasarkan Undang-Undang RI Nomor 20 Tahun 2003 tentang sistem Pendidikan Nasional, Pendidikan formal adalah jalur Pendidikan yang terstruktur dan berjenjang yang terdiri atas
Pendidikan dasar, Pendidikan menengah, dan Pendidikan tinggi. Sedangkan Pendidikan nonformal berfungsi untuk mengembangkan potensi peserta didik dengan penekanan pada penguasaan pengetahuan dan keterampilan fungsional dan mengembangkan sikap dan kepribadian fungsional

Pendidikan dapat diartikan sebagai mendidik, membimbing, mengajar dan melatih yang tertuang dalam proses Pendidikan di sekolah. Sekolah salah satu Pendidikan yang termasuk kedalam kelompok formal merupakan sarana dalam rangka pencapain tujuan Pendidikan dengan melalui proses kegiatan belajar mengajar. (Hadiyanto Herman, 2014).

Ada banyak fungsi dari Pendidikan, yang salah satunya yaitu Pendidikan berfungsi untuk membantu siswa agar dapat merencanakan apa yang akan dicitacitakan dan karier dimasa yang akan datang. Menurut Hurlock dalam (triyono, 2016) juga mengatakan bahwa minat Pendidikan remaja dipengaruhi oleh minatnya terhadap pekerjaan.

Menurut Yusuf (triyono, 2016) mengartikan bahwa Pendidikan adalah Pre-Ocupation. Yang dimana 
dunia Pendidikan itu awal penentuan karier seseorang. Yang itu berarti kehidupan manusia sebagai seorang siswa merupakan persiapan untuk memasuki kehidupan dunia perkerjaan. Sering muncul sebuah pertanyaan "apa cita-cita mu setelah dewasa nanti?".

Menurut Yusuf dan Juntika dalam (triyono, 2016) mengatakan bahwa pendidikan merupakan faktor yang penting dalam perkembangan karier individu, melalui individu Pendidikan dapat mewujudkan citacita yang diharapkan. Dengan ditempuhnya Pendidikan formal atau sekolah diharapkan dapat berperan pending dalam mengantarkan siswa untuk mencapai cita-cita yang diharapkannya.

Pendidikan Sekolah Dasar merupakan salah satu Pendidikan formal pada level tahap awal yang ada di Indonesia. Disinilah anak-anak mulai menganal macam-macam pekerjaan dan mempunyai cita-cita.

Cita-cita merupakan sebuah keinginan yang ada di dalam pikirian seseorang (Illyas et al., 2020). Sebagian orang berpikir cira-cita adalah tujuan hidup yang harus dicapai Ketika besar nanti (Selian et al., 2021). Cita-cita tidak hanya bagi orang-orang yang berkecukupan saja tetapi bisa dimiliki oleh siapa saja (Defira, 2021).

Cita-cita

umumnya diperkenalakan pada saat Sekolah Dasar. Mengenalkan Cita-cita kepada siswa Sekolah Dasar bisa menggunakan cara seperti mengenalkan profersi atau karier atai cita-cita kepada siswa. Siswa sekolah dasar biasanya memiliki cita-cita seperti, Guru, bidan, perawat, dokter, pilot, polisi, tantara dan lain sebagainya (Illyas et al., 2020). Waaupun pada kenyaataanya pola Pendidikan formal belum yang sedang dijalankan oleh anak selama sekolah formal masih banyak yang terbatas masih banyak yang terbatas kepada terisinya informasi mengenai pengetahuan yang secara umum. Tetapi pada Pendidikan formal belum diarahkan kepada memberikan gambaran atapun inspirasi mengenai cita-cita ataupun karir yang diharapkan kelak (Supriyadi et al., 2019)

cita-cita yang dimiliki merupakan sebuah motivasi untuk mereka agar semakin giat untuk belajar. Tidak ada seorangpun yang memiliki cita-cita untuk menjadi penjahat ataupun pengangguran. 
Akan tetapi, sebuah cita-cita sangat dipengaruhi oleh faktor-faktor yang ada di sekitar siswa. Faktorfaktor ini yaitu faktor internal dan eksternal. Faktor internal yaitu minat, bakat, dan pengalaman yang dimiliki. Faktor eksternal yaitu keluarga dan lingkungan sekitar (Damanik, 2016).

menurut mulyanigtyas cita-cita dipengaruhi beberapa faktor seperti:

(1) Latihan dan lingkungan sejak kecil;

(2) ambisi orang tua; (3) tokoh idola; (4) persaiangan dengan orang lain; (5) tradisi, norma, adat dan kebiasaan yang berlaku; (6) pengalamanpengalaman masa lalu; dan (7) minat dan nilai-nilai yang dianut (Gulo, 2018; Lestari, 2016).

Keluarga merupakan salah satu faktor terbentuknya cita-cita anak tanpa disadari khususnya orang tua. Banyaknya waktu yang kita lakukan dalam sehari-hari dengan keluarga hal ini akan mempengaruhi cita-cita anak. Latar belakang pekerjaan orang tua dan juga kondisi ekonomi sangat mempengaruhi cita-cita anak.

Dari faktor keluarga seperti kondisi ekonomi keluarga, latar Pendidikan orang tua, dan pekerjaan orang tua sangat mempengaruhi citacita siswa Sekolah Dasar.
Menurut Husni dalam (Baiti, 2020) secara umum arti dari pekerjaan adalah sebuah kegiatan aktif yang dapat dilakukan oleh manusia. Secara sempit arti dari pekerjaan adalah kerja yang dapat menghasilkan sebuah karya bernilai imbalan dalam bentuk uang bagi seseorang.

Berdasarkan latar belakang masalah ini maka penulis tertarik untuk meneliti "Hubungan antara pekerjaan orang tua dan cita-cita siswa”. Penelitian ini bertujuan untuk mengetahui adakah hububungan antara pekerajaan orang tua dan citacita siwa.

Penelitian ini berfokus pada pekerjaan ayah, karena hasil dari responden hampir semua responden ibunya tidak bekerja (ibu rumah tangga)

\section{B. Metode Penelitian (Huruf 12 dan \\ Ditebalkan)}

Untuk mengetahui hubungan antara pekerjaan orang tua terhadap Cita-cita anak, maka penenilis melakukan Penelitian ini dengan menggunakan metode kuantitatif jenis deskriptif korelasional. Deskripsi korelasional adalah penenilaian yang dimaksudkan untuk mengumpulan informasi-informasi mengenai status 
yang berhubungan dengan suatu gejala yang ada. Gejala yang dimaksud yaitu gejala yang menurut apa adanya pada saat penelitian ini dilakukan.

Penelitian ini dilakukan melalui 7 tahahap yaitu: (1) merumuskan masalah penelitian dan menentukan tujuan survey; (2) menentukan konsep dan juga hipotesa serta menggalai kajian Pustaka; (3) pengambilan sampel; (4) pembuatan kuesioner; (5) pekerjaan lapangan; (6) pengolahan data; dan (7) Analisa dan pelaporan (Mustika lka \& Lestari Dwi Riana, 2016)

Teknik pengumpulan data dalam penelitian ini yaitu menggunakan kueisioner. Menurut suyanto dan sutinah Kuesioner berisikan daftar pertanyaan yang tersruktur dengan adanya alternatif jawaban yang sudah di sediakan sehingga responden hanya tinggal memilih jawaban yang disediakan sesuai dengan aspirasi, keadaa, sikap, persepsi, atau pendapat pribadinya (Nugroho, 2018).

Teknik analisis data dalam penelitian ini menggunakan uji asumsi klasik berupa uji normalitas kemudian uji statistic non parametrik Chi-square dengan taraf signifikasi 0,05
Penelitian ini dialaksakan pada siswa kelas 4 SDN Sukalarang yang berjumlah 48 orang, sampel berjumlah 18 orang, yang dipilih dengan sesuai jumlah siswa yang sekolah pada saat pengujian instrument Penelitian ini dilaksanakan pada tanggal 1 November 2021.

\section{Hasil Penelitian dan Pembahasan (Huruf 12 dan Ditebalkan)}

Hail dari penelitian yang dialaksanakan pada tanggal 1 November 2021 di kelas IV B SDN Sukalarang.

Sebelum melalukan uji statistik non parametrik Chi-square, peneliti melakukan uji asumsi klasik yaitu uji normalitas. Uji normalitas dalam penelitian ini menggunakan metode statistic one sample Kolmogorov Smirnov (K-S). Uji One Sample Kolomogorov Smirnov digunakan untuk mengetahui distribusi data, apakah mengikuti distribusi normal, poisson, uniform, atau exponential. Dalam hal ini untuk mengetahui apakah distribusi residual terdistribusi normal atau tidak. Residual berdistribusi normal jika nilai signifikansi lebih besar dari 0,05. Jika nilai signifikansi lebih kecil dari 0,05 
maka nilai residual tersebut tidak normal.

$$
\text { Kelebihan menggunakan }
$$

metode ini adalah sederhana dan tidak menimbulkan perbedaan persepsi di antara satu pengamat dengan pengamat yang lain, yang sering terjadi pada uji normalitas dengan menggunakan grafik.

Tabel 1

Hasil Uji Noralitas

One-Sample Kolmogorov-Smirnov

Test

\begin{tabular}{|c|c|c|}
\hline \multicolumn{3}{|c|}{ One-Sample Kolmogorov-Smirnov Test } \\
\hline \multicolumn{3}{|r|}{$\bar{Y}$} \\
\hline $\mathrm{N}$ & & 18 \\
\hline \multirow{3}{*}{$\begin{array}{c}\text { Normal } \\
\text { Parameters }\end{array}$} & Mean & 34.3333 \\
\hline & Std. & 3.66221 \\
\hline & Deviation & \\
\hline \multirow{3}{*}{$\begin{array}{c}\text { Most Extreme } \\
\text { Differences }\end{array}$} & Absolute & .150 \\
\hline & Positive & .150 \\
\hline & Negative & -.136 \\
\hline Test Satistic & & .150 \\
\hline Asymp.Sig. (2- & & $200^{c, d}$ \\
\hline
\end{tabular}

a.Test distribution is Normal.

b.Calculated from data.

c.Lilliefors Significance Correction.

d. This is a lower bound of the true significance.

Pada tabel diatas diketahui bahwa data dengan KolmogropSmirnov pada variable pekerjaan orang tua terhapat cita-cita anak dengan pengujian hasil uji normalitas termasuk kedalam distribusi normal.
Hal ini di karenakan nilai signifikasinya lebih besar dari 0,05 yaitu sebesar 0,200 .

Pada tabel 2 terdapat hasil penelitian mengenai pekerjaan orang tua dengan cara menggunakan kuesioner menunjukan sebesar $72,22 \%$ atau sebanyak 13 responden memiliki orang tua berlatar belakang pekerjaan pada kelompok rendah. Dan sebesar $27,7 \%$ atau sebanyak 5 memiliki orang tua berlatar belakang pekerjaan pada kelompok tinggi.

Tabel 2

pekerjaan orangtua siswa kelas IV B SDN Sukalarang

\begin{tabular}{|c|c|c|c|}
\hline $\begin{array}{c}\text { Jenis } \\
\text { pekerjaan }\end{array}$ & $\begin{array}{c}\text { Tingkat } \\
\text { pekerjaa } \\
n\end{array}$ & $\begin{array}{c}\text { frekun } \\
\text { si }\end{array}$ & $\begin{array}{c}\text { persenta } \\
\text { se }\end{array}$ \\
\hline $\begin{array}{l}\text { Buruh, } \\
\text { petani, } \\
\text { sopir, } \\
\text { pensiuna } \\
\text { n, } \\
\text { pedagang } \\
\text {, lain-lain }\end{array}$ & Rendah & 13 & $72,22 \%$ \\
\hline $\begin{array}{c}\text { Guru, } \\
\text { pegawai } \\
\text { swastam } \\
\text { non guru, } \\
\text { wiraswast } \\
\text { a, } \\
\text { pendeta, } \\
\text { bidan, } \\
\text { perawat }\end{array}$ & Sedang & 0 & $0 \%$ \\
\hline
\end{tabular}




\begin{tabular}{|lll|}
\hline PNS non tinggi & 5 & $27,78 \%$ \\
guru, & & \\
dosen, \\
dokter, \\
advokat, \\
notaris, \\
hakim & \\
\hline Jumlah & & \\
\hline
\end{tabular}

Tabel 3

cita cita siswa

\begin{tabular}{|ccc|}
\hline \multicolumn{3}{|c|}{ Cita-cita siswa } \\
\hline & frekuensi & persentase \\
\hline Rendah & 1 & $5,55 \%$ \\
\hline Sedang & 10 & $55,56 \%$ \\
\hline Tinggi & 7 & $38,89 \%$ \\
\hline Jumlah & 18 & $100 \%$ \\
\hline
\end{tabular}

Hasil dari kuesioner untuk variable cita -cita siswa seperti pada tabel 3. Sebagian besar siswa aatau sebanyak 55,56\% atau sebanyak 10 responden memiliki cita-cita dengan katergori sedang, lalu $38,89 \%$ atau sebanyak 7 reponden memiliki citacita dengan kategori tinggi, dan Sebagian kecil responden yaitu 5,55\% atau sebanyak 1 orang responden memiliki cita-cita ketegori rendah. Banyak responden yang memiliki citacita yang termasuk ke dalam tingikat pekerjaannya sedang. seperti Guru, pegawai swastam non guru, wiraswasta, pendeta, bidan, perawat
Tabel 4

Hasil analisis chisquare pekerjaan orang tua terhadap cita-cita siswa

\begin{tabular}{|llll|}
\hline \multicolumn{4}{|c|}{ Chi Square Tests } \\
\hline & Value df & $\begin{array}{l}\text { Asympototic } \\
\text { Significance } \\
\text { (2-sided) }\end{array}$ \\
\hline $\begin{array}{l}\text { Pearson } \\
\text { Chi-Square }\end{array}$ & 4.969 & 2 & .083 \\
\hline $\begin{array}{l}\text { Likekihood } \\
\text { Ratio }\end{array}$ & & & \\
\hline $\begin{array}{l}\text { Linear-by- } \\
\text { linear }\end{array}$ & 4.272 & 1 & .074 \\
Association & & & \\
\hline $\begin{array}{l}\mathrm{N} \text { of Valid } \\
\text { Cases }\end{array}$ & & & \\
\hline
\end{tabular}

Dari tabel 4 di atas dapat diperoleh dengan nilai Chi-Square hitung sebesar 4,969 dan nilai Asym.Sig 0,083. Karena nilai Asym Sig sebesar 0,083 sehingga dapat disimpulkan bahwa pekerjaan orang tua tidak berpengaruh terhadap citacita siswa kelas 4B SDN Sukalarang.

Berdasarkan analisis chi square crosstab yang ada di atas, maka jenis pekerjaan orang tua juga sama sekali tidak memiliki pengaruh terhadap cita cita siswa kelas 4B SDN Sukalarang. Hal ini dapat menunjukan bahwa pekerjaan ataupun profesi apapun yang digeluti oleh para orang tua tidak mempengaruhi cita-cita yang dimiliki 
oleh paara siswa kelasn 4B SDN Sukalarang.

Para siswa memiliki keingin dan juga keputusan sendiri tanpa adanya pengaruh dari faktor latar belakarang pekerjaan orang tua. Golongan pekerjaan dan juga jenis pekerjaan yang di geluti olhe para orang tua sama sekali tidak mempengaruhi citacita para siswa.

Pekerjaan yang masyarakat anggap tinggi ataupun rendah sama sekali tidak memperngaruhi cita-cita para siswa yang mereka miliki.

Siswa memiliki wawasan dan kesempatan-kesempatan yang luas atas apa uang mereka harapkan dimasa depan nanti. Pada jenis pekerjaan orang tua yang termasuk ke dalam tingkat pekerjaan rendah dan menghasilkan keadaan perekonomian yang tidak stabil dalam keluarga bukalah menjadi alasan para siswa untuk mempunyai cita-cita setinggi mungkin. Begitu pula sebaliknya, para siswa yang orang tuanya memiliki latar belakarang pekerjaan yang termasuk ke dalam katergori tinggi belum tentu mempunyai cita-cita yang tingga dimasa depan.

Tidak adanya sama sekali pengaruh pekerjaan orang tua terhapat cita-cita siswa juga bisa saja di sebabkan oleg hal lain. Seperti para orang tua yang bekerja terlalu sibuk sehingga tidak memiliki waktu untuk membagikan cerita mengenai pekerjaannya yang di tekuni. Hal ini juga di dukung oleh Albertus (Pamuji, 2018) orang tua bahkan guru tidak berhak untuk memaksakan cita-cita terhadap anak. Berikanlah kebebasan untuk anak anak yang ingin menjadi apapun. Tugas orang tua dan guru dalam cita-cita anak yaitu memberikan edukasi bagaimana proses pencapaian cita-cita tersebut dan berikan sedikit cerita mengenai pekerjaan yang di cita-citakan oleh anak.

Cerita mengenai pekerjaan orang dua dapat memberikan gambaran mengenai dunia kerja yang akan dihadapi oleh siswa nanti. Bisa saja bidang pekerjaan yang saat ini di tekuni oleh para orang tua tidak diminati oleh anak, tetapi apa bila dengan berbagi cerita kepada anak tentang pekerjaannya bisa memperikan anak gambaran dan juga inspirasi terhadap cita-citanya.

Para orang tua perlu juga untuk memberikan gambaran mengenai pekerjaan yang menjadi cita-cita anak. Hal ini bertujuan untuk anak dapat mengenali lebih jauh profesi yang 
dicita-citakan oleh anak. Dengan adanya informasi-informasi megenai pekerjaaanya di mana depan anak akan bisa memantapkang Langkah yang akan diambil dikemudian hari. Hal ini juga di dukung oleh penelitian terdahulu yang dilalukan oleh cempaka (Cempak, 2018) yaitu berkomunikasi anatara orang tua dan juga anak mengenai cita-cita anak.

dalam penelitian yang dilakukan oleh budi dijelaskan bahwa adanya hubungan antara pola asuh orang tua terhadap pemilihan karir siswa (Kurniawan et al., 2019). Sehingga dapat diartikan bahwa cita-cita siswa tidak memliki hubungan dengan pekerjaan orang tua tetapi tergantung pola asuh dari orang tua.

Penelitian terdahulu Defira (Defira, 2021) juga mengatakan bahwa cita-cita murni dari kemamuan anak itu sendiri, tidak adanya pengaruh dari orang lain.

Sebuah pemilihan cita-cita untuk masa dapan harus sesuai dengan minat dan bakat, kepribadia, nilai-nilai kehidupan, keadaan fisik atau kemampuan yang dimiliki (Rahayu, 2012). Hal ini bertujuan agar pada saat nanti berkarir akan berjalan dengan sempurna.

\section{E. Kesimpulan}

Berdasarkan dari penelitian yang di lakukan dapat disimpulkan bahwa latar belakang pekerjaan orang tu sama semakali tidak memilki pengaruh terhadap cita-cita siswa kelas 4B SDN Sukalarang. Pekerjaan orang tua baikyang termasuk kedalan kategori tinggi ataupun kategori rendah sama sekali tidak mempengaruhi terhadap cita-cita anak.

Anak memiliki cita-cita atas kemauannya sendiri dan keputusannya sendiri. Tanpa melihat apa pekerjaan orang tua mereka.

\section{DAFTAR PUSTAKA}

Baiti, N. (2020). Pengaruh

Pendidikan, Pekerjaan Dan Pola Asuh Orang Tua Terhadap Kemandirian Anak. JEA (Jurnal Edukasi AUD), 6(1), 44. https://doi.org/10.18592/jea.v6i1. 3590

Cempak, P. G. (2018). Analisis

Resepsi Audiens Terhadap

Komunikasi Orang Tua dan Anak

Terkait Cita-Cita Anak dalam

Film Animasi Coco [Universitas

Gajah Mada].

http://etd.repository.ugm.ac.id/

Damanik, E. K. (2016). Pengaruh

Jenis Kelamin, Motivasi Belajar dan Bimbingan Karier Terhadap 
Cita-Cita Siswa. Universitas Sanata Dharma Yogyakarta.

Defira, Z. (2021). Cita-Cita Anak Panti Asuhan Puteri Aisyiyah Wilayah. Cross-Border, 4(2), 291-303.

Fansen. (2020). Pengaruh Pekerjaan Orang Tua Terhadap Kemandirian Anak Usia Dini Di Paud Yasporbi Kota Bengkulu. Institut Agama Islam Negeri (IAIN) Bengkulu.

Gulo, I. S. P. J. (2018). Hubungan Antara Minat Belajar, Cita-Cita Siswam Kompetensi Guru, Komunitas Teman Sebaya Dengan Motivasi Belajar Sisaw SMA Negeri Di Kabupaten Sleman. Universitas Sannata Dharma Yogyakarta.

Hadiyanto Herman. (2014). Pengaruh Pendidikan, Pekerjaan dan Pendapatan Orang Tua Terhadap Prestasi Belajar Ekonomi Pada Siswa SMA. Jurnal Ekonomi Pendidikan Dan Kewirausahaan, 2(2), 171-185. https://journal.unesa.ac.id/Index. Php/Jepk/Article/Download/728/5 76

Illyas, A., Aldrian, A., Hidayah, N., \& Kurniati, S. B. (2020). POCITA : Mengenalkan Cita-Cita dan Lingkungan Sejak Dini. 3(2), 181-186.

Kurniawan, B. C., Dahlan, S., \& ... (2019). Hubungan Pola Asuh Orangtua dengan Pemilihan Karir Siswa. ALIBKIN (Jurnal .... http://jurnal.fkip.unila.ac.id/index. php/ALIB/article/view/17915

Lestari, C. P. (2016). Pengaruh Tingkat Pendidikan Orang Tuan, Jenis Pekerjaan Orang Tua, dan Motivasi terhadap Cita-Cita Siswa Setelah Menyelesaikan Pendidikan Di SMK. Universitas Sanata Dharma Yogyakarta.

Mustika lka, \& Lestari Dwi Riana. (2016). Hubungan Minat Baca dan Kebiasaan Membaca Karya Sastra Terhadap Kemampuan Menulis Puisi. Semantik (Jurnal IImiah Program Studi Pendidikan Bahasa dan Sastra Indonesia, 5(6), 17.

Nugroho, E. (2018). Prinsip-Prinsip Menyusun Kuesioner (cetakan pe). UB Press.

Rahayu, S. O. (2012). Pengambilan Keputusan Karir Menjadi Guru Ditinjau Dari Latar Belakang Profesi Orang Tua [Universitas Muhammadiyah Surakarta].

Selian, S. R., Y, T. K., \& Rizka, S. M. (2021). Pengemabnagan Busy Book Sebagai Media Pembelajaran Mengenalkan Cita-Cita Kepada Anak. Jurnal Ilmiah Mahasiswa Pendidikan Anak Usia Dini 2, 6, 51-59.

Sidik, S., P, W. A., Ekonomi, F., \& Islam, U. (2013). Motivasi Menentukan Dan Meraih CitaCita Bagi Remaja. Motivasi Menentukan Dan Meraih CitaCita Bagi Remaja, 2(1), 23-26. f 
Supriyadi, T., Apriyenti, L. U., Rismalinda, Hutahaean, E. S. H., Pertiwi, Y. W., Gina, F., Fitriyanto, M., \& Anifa. (2019).

Cita-citamu Mau Jadi Apa? : Mengajarkan Cita-cita Pada Anak-Anak Komunitas Rumah Pelangi Bekasi. 131-139.

triyono, tri. (2016). Kontribusi

Dukungan Orang Tua Terhadap

Tingkat Aspirasi Pendidikan

Lanjutan. Jurnal Pelangi, 8(2),

178-186. K 